\title{
Learning to live with AIDS
}

\section{New approaches may be needed if AIDS is to be controlled.}

\section{Combating AIDS: Communication Strategies in Action \\ by Arvind Singhal \& Everett M. Rogers

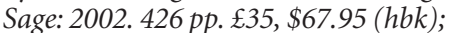 $\mathfrak{1} 14.99, \$ 29.95$ ( $p b k$ )}

\section{Living with the AIDS Virus: The Epidemic and the Response in India \\ edited by Samiran Panda, Anindya Chatterjee \& Abu S. Abdul-Quader Sage: 2002. 204 pp. $227.50, \$ 45$ (hbk); $£ 14.99, \$ 24.95(p b k)$ \\ Ritu Priya}

Efforts to control AIDS in developing countries have largely had an international basis. There is a vast literature on AIDS-control strategies, but the most visible reports have been from international agencies, looking at the magnitude of the epidemic and the 'best practices' for its control. Advocacy material and manuals for training programme managers and AIDS workers abound. But only a small segment consists of rigorous analysis of the interventions undertaken so far.

The approach set out during the 1980s has thus become a set of globally communicated homilies that are universally linked with AIDS-control work. These include valuable principles such as respecting human rights in disease control; providing information to all; positing a public-health problem as more of a development issue than a medical issue; establishing partnerships between different social groups; and focusing on the conditions of the socially marginalized sections of the community.

Translating these principles into reality, however, requires consideration of the specific context within which they are to be applied. For instance, the cost of antiviral drug regimens for HIV and AIDS is important in regions where medical care is assured, but elsewhere it can distract attention from the essential issues of delivering basic care and treating opportunistic infections. Likewise, the promotion of sexual freedom may be liberating in some contexts but is detrimental to the rights of women under conditions where they have no other freedoms and so are most vulnerable to exploitation.

National AIDS-control programmes the world over basically follow a similar set of strategies. The programmes need to be based on a contextualized assessment of the existing resources - such as materials, infrastructure, support systems and value frameworks - that are available in each community and in society at large.

Combating AIDS draws upon material on AIDS control in South Africa, Kenya, Brazil,

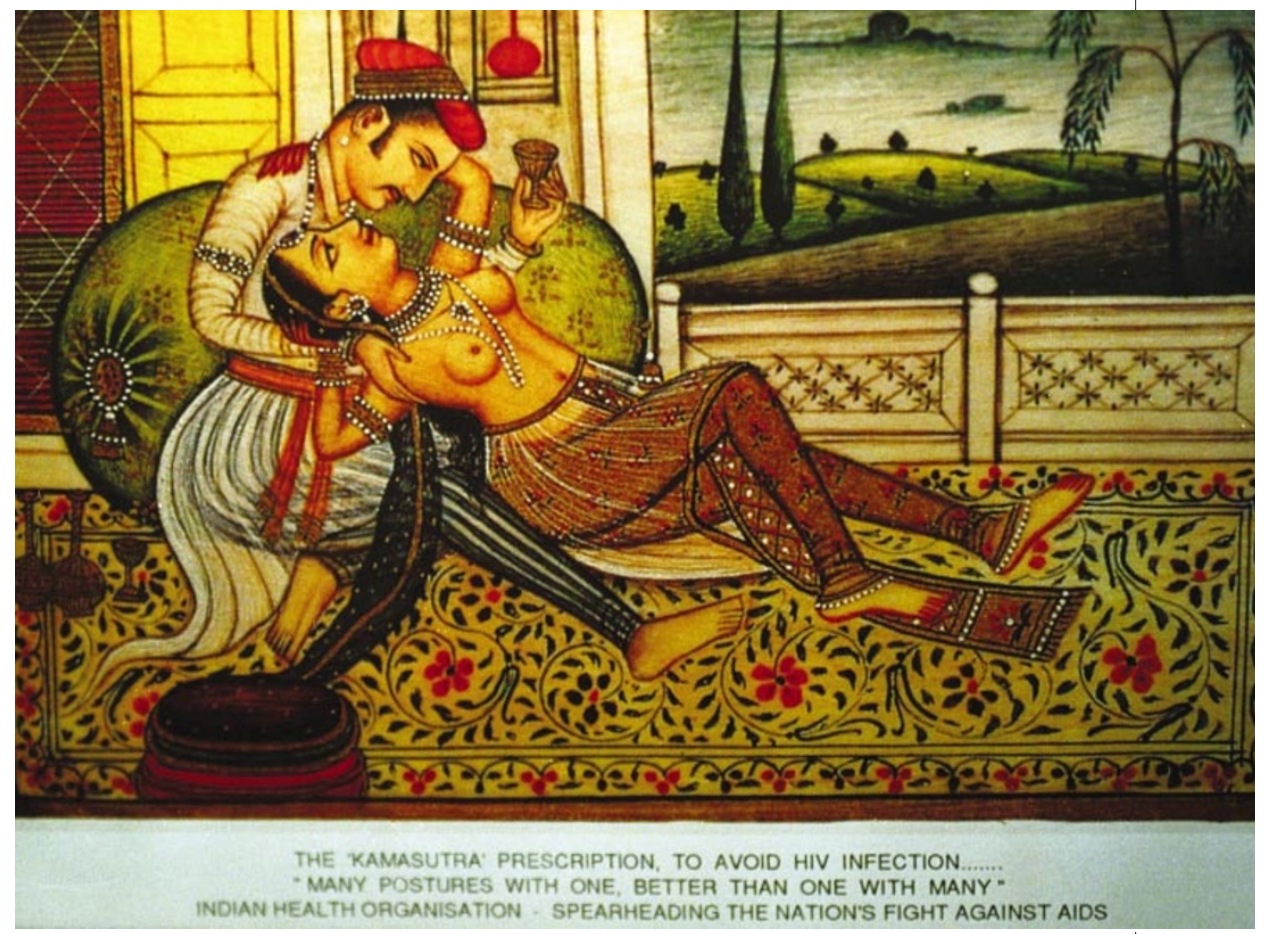

Local knowledge: considering cultural factors can make communication about AIDS more effective.

Thailand, Cambodia and India to extract universal lessons for developing countries. Its focus is on communication strategy, but half of the book is devoted to discussing the global history of the epidemic, including its biomedical, clinical, epidemiological and policy dimensions. In these chapters the book is disappointing. The strong chapters are those on cultural strategies and entertainment-education, which draw attention to the limitations of approaches that ignore cultural strengths and the opportunities that they provide for positive intervention. The book's illustrations of innovations with existing non-verbal communication in collectivistic cultures - for example, through dress codes that indicate pregnancy and hence the husband's responsibility to his wife at such times - demonstrate sensitivity to cultures other than those of Western Europe and the United States.

However, the authors' evaluation of communication as an effective intervention for controlling AIDS is not convincing. The evidence is usually anecdotal, and where a field trial is cited, the data for comparison across the study and control groups are not provided. Indices such as self-reported shifts to safer practices are not reliable, as respondents are likely to give the 'expected answers' in the post-intervention period.

In areas of high prevalence, spontaneous declines in unsafe behaviours as a result of direct exposure to disease and death on a large scale cannot be discounted. In areas of low HIV prevalence, declines in the rates of infection with sexually transmitted diseases do not necessarily indicate that the sustained low HIV seropositivity is due to the communication intervention; other epidemiological factors could be involved. This is not to say that communication to the public is of no value, but that its limitations when the wider environment is not conducive or is even contrary to such intervention need to be recognized.

The book contains many paradoxes. The authors espouse the view that "the forest is more important than the individual tree", yet their own focus remains at the 'micro' level. They critique the emphasis on biomedical dimensions but remain preoccupied with the use of condoms and anti-retroviral drugs as the final goal of AIDS communication. And their blurring of the distinction between the use of spirituality and social values, and the use of the power of religious leaders for promoting responsible sexuality will worry those concerned about human rights.

Living with the AIDS Virus presents a more detailed analysis of the effort to control AIDS in India, with contributions from those who have been involved with the campaign over several years. A contextual sensitivity 
and an attempt to identify the lacunae in existing approaches are revealed in most of the chapters, especially those on the government's response, the role of non-governmental organizations, community responses in Mumbai City, and interventions with gay men. These chapters demonstrate the complexity of the issues involved, and contrast with the superficial analysis presented by Combating AIDS. The negative impact of the information, education and communication strategy in terms of increasing fear and stigma is recognized. Living with the AIDS Virus also highlights the limitations of 'targeted interventions' as the target groups tend to be stigmatized. Instead, it is better to address communities at large; for example, rather than target truckers, it is better to reach societies along transport corridors.

Both books acknowledge that AIDScontrol strategies have generated stigma, ignored the creation of capacities for care and support, and been gender insensitive. But despite this, both books propose managerial and technocratic solutions that do not question the existing perspective. If we do not want to prescribe without a diagnosis, we need to ask why such measures were adopted in the first place.

Alternative perspectives with a societal rather than a programme-oriented approach have also been articulated since the 1980s. They integrate the biomedical and social dimensions rather than dichotomizing them, and view preventive and curative measures as an integral whole, and means and ends as complementary. However, neither book cites the people's movement groups and academics who espouse such perspectives, and who warned early on of the limitations that are now being widely realized. Instead, the books attribute the positive influence to international funding agencies or to local non-governmental organizations, which have been influential in shaping the response in the first place. AIDS control has been led more by emotion, instinct and international politics than by scientific evidence or contextual needs. Denying this 'politics of knowledge' can only allow the suffering caused by AIDS to continue unabated.

Combating AIDS is slickly written using communicators' theories, taking the reader step-by-step through various arguments, and using repetition to ingrain them in the reader's mind. It is likely to interest local programme managers, as it provides examples of a wide range of interventions that comply with the homilies of current AIDScontrol thinking. Living with the AIDS Virus, although less elegantly written, provides more food for thought for policy-makers, researchers and programme managers. Both books should interest the general reader. Ritu Priya is at the Centre of Social Medicine and Community Health, Jawaharlal Nehru University, New Delhi 110067, India.

\section{Designer darwinism}

\section{Darwin and Design: Does \\ Evolution Have a Purpose?}

by Michael Ruse

Harvard University Press: 2003. 384 pp.

$\$ 29.95, £ 19.95$

\section{Mark Ridley}

Design — what biologists call 'adaptation' - is an obvious feature of life. People have probably been thinking about it for as long as they have been thinking about anything. Classically, it provided the basis of the 'argument from design', one of five arguments put forward for the existence of God. Darwin undermined that argument, but it has enjoyed something of a revival in the latest version of creationism, known as 'intelligent design creationism'.

Michael Ruse is a philosopher of biology, and his broad-ranging book covers several themes. He distinguishes the 'argument to complexity' - the factual observation that complex adaptations, such as eyes and wings, exist in nature — from the 'argument from design', the theological inference from that fact that God exists. Ruse traces the history of these two arguments from their earliest forms in the hands of Plato and Aristotle, through Galen and Thomas Aquinas, on to David Hume, Immanuel Kant and William Paley, followed by Georges Cuvier and Richard Owen, and then Darwin and his followers in the modern synthesis.

After the history, Ruse takes a look at modern research on adaptation, and at its 'formalist' critics, who think that organisms are shaped by non-adaptive laws of form, rather than by adaptation to the environment. He ends with two chapters on modern theologians, including the intelligent-design creationists.

There is no central argument to unify the book, but Ruse holds a consistently darwinian position against all its critics. Adaptation exists, he says; it matters; it is not explained by God; it is explained, and with exemplary scientific propriety, by natural selection; and it is a legitimate topic for scientific research. The various people who have argued otherwise are making various kinds of mistake.

The book is written for philosophers and theologians as well as scientists. Indeed, the book will help to broaden the minds of most scientific readers. I doubt whether anyone else has read up on quite the range of authors that Ruse has, and he writes about them clearly and non-technically.

Ruse also advances certain theses along the way that will particularly interest Nature readers, and I'll concentrate on them. One question concerns adaptationist research. The biologists who do this research often argue not only that they find adaptation interesting, but that it is peculiarly important in biology. Successful adaptationist research is explanatory in a way that makes most mechanistic research look descriptive. And any big theory about life has to be able to explain adaptation.

On this topic, Ruse gives a sympathetic hearing to the critics who, he says, "would raise the objection that adaptation and the associated design metaphor have their roots in British natural theology of the preDarwinian era, and they would ask again why, in the secular world of the twentyfirst century, we should be bound by this retro-thinking." This seems to be close to confusing the contexts of discovery and of justification. Adaptationism may have its roots in predarwinian anglican theology, but that does not make it false. German textual scholarship may have its roots in lutheran theology, but that does not reduce the value of the texts.

I think the strongest argument that the critics can make is not that adaptation is unimportant, just one problem among many, but that it has been solved. This may level the playing field for adaptationist and non-adaptationist research now, but it does not reduce the conceptual importance of adaptation for understanding life.

Research into adaptation often uses optimality models, or something like them. It might aim to understand the form of an eye, for instance, on the assumption that eye shape is optimized for forming images. One common interpretation of this research is that it aims to understand how, and not whether, organisms are adapted. Ruse disagrees. "It is fairer to say that a twoway process is at work here.

We adopt a background assumption of adaptationism and then

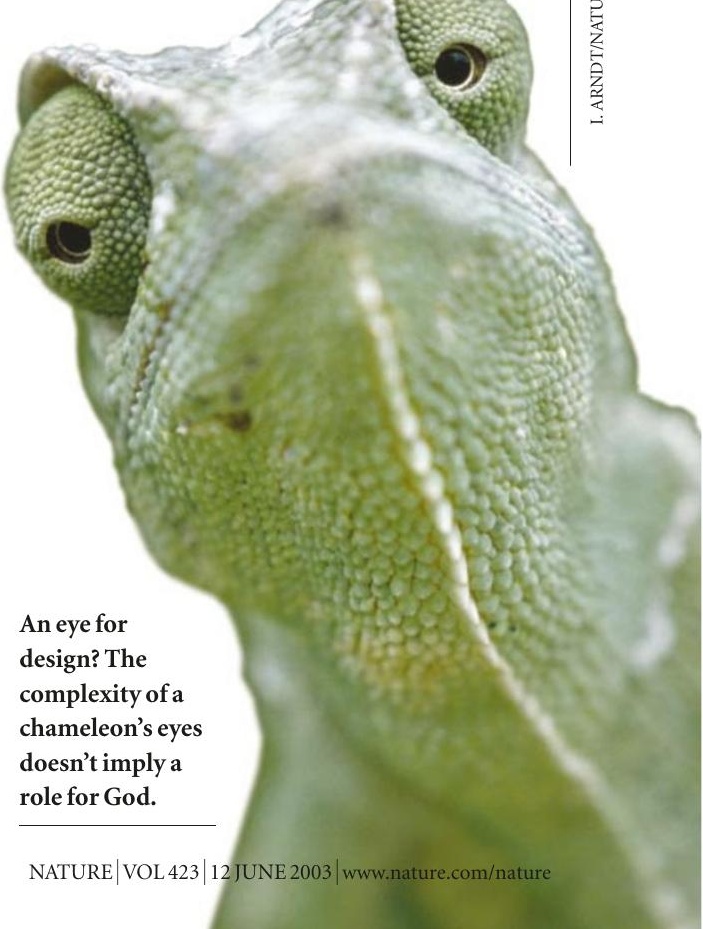

